\title{
Circulação e cidadania: modos de comunicar na cidade
}

Circulation and citizenship: ways of communicating in the city

Circulación y ciudadanía: formas de comunicación en la ciudad

\author{
Raquel Paiva ${ }^{1, a}$ \\ raquelpaiv@gmail.com | https://orcid.org/0000-0001-8786-751X \\ Leandro José Carmelini ${ }^{1, b}$ \\ lcarmelini@gmail.com | https://orcid.org/o0o0-0002-5814-3325 \\ ${ }^{1}$ Universidade Federal do Rio de Janeiro, Escola de Comunicação. Rio de Janeiro, RJ, Brasil. \\ a Doutorado em Comunicação pela Universidade Federal do Rio de Janeiro. \\ ${ }^{\text {b } M e s t r a d o ~ e m ~ C o m u n i c a c ̧ a ̃ o ~ e ~ C u l t u r a ~ p e l a ~ U n i v e r s i d a d e ~ F e d e r a l ~ d o ~ R i o ~ d e ~ J a n e i r o . ~}$
}

\section{Resumo}

Este texto pretende discutir, a partir de uma perspectiva comunicacional, a relação entre circulação urbana e cidadania. Em um primeiro momento introdutório, nos deteremos principalmente nos conceitos de sistemas comunicacionais, comum e comunicação. Em seguida, pensaremos como o paradigma moderno de circulação, histórica e contemporaneamente, interfere na organização do comum e nos espaços da cidade de modo a privilegiar circuitos domésticos e de consumo em detrimento de usos e ocupações mais livres do espaço público. Por fim, discutiremos sobre a ideia de cidadania no Brasil para pensar com há uma relação explícita no modo como se circula na cidade, se constitui o comum urbano e se dispõe de certos direitos, especificamente o de liberdade de locomoção, ou, se quisermos, o direito de ir e vir.

Palavras-chave: Comunicação; Circulação; Cidade; Direito à cidade; Cidadania. 


\begin{abstract}
This text intends to discuss, from a communicational perspective, the relationship between urban circulation and citizenship. In the first introductory moment, we will focus mainly on the concepts of communication, common and communication systems. Next, we will think about how the modern paradigm of circulation, historically and contemporarily, interferes with the organization of the commons and the city spaces in order to privilege domestic and consumption circuits over the freer uses and occupations of public space. Finally, we will discuss about the idea of citizenship in Brazil to think with there is an explicit relation in the way it circulates in the city, if it constitutes the urban common and if it has certain rights, specifically freedom of movement, or, if we wish, the right to come and go.
\end{abstract}

Keywords: Communication; Circulation; City; Right to the city; Citizenship.

\title{
Resumen
}

Este texto pretende discutir, desde una perspectiva comunicacional, la relación entre la circulación urbana y la ciudadanía. En el primer momento introductorio, nos centraremos principalmente en los conceptos de comunicación, sistemas comunes y de comunicación. A continuación, pensaremos cómo el paradigma moderno de la circulación, histórica y contemporáneamente, interfiere con la organización de los espacios comunes y municipales para privilegiar los circuitos domésticos y de consumo sobre los usos y ocupaciones más libres del espacio público. Finalmente, discutiremos sobre la idea de ciudadanía en Brasil para pensar que existe una relación explícita en la forma en que circula en la ciudad, si constituye el común urbano y si tiene ciertos derechos, específicamente la libertad de movimiento o, si lo deseamos, El derecho a ir y venir.

Palabras clave: Comunicación; Circulacion Ciudad; Derecho a la ciudad; Ciudadanía

INFORMAÇÕES DO ARTIGO

Contribuição dos autores: os autores são responsáveis por todo o texto.

Declaração de conflito de interesses: não há.

Fontes de financiamento: não houve.

Considerações éticas: não há.

Agradecimentos/Contribuições adicionais: não há.

Histórico do artigo: submetido: 25 dez. 2018 | aceito: 20 maio 2019 | publicado: 12 set. 2019.

Apresentação anterior: a primeira versão deste trabalho foi apresentada oralmente no Congresso Ibero-americano de Comunicação (IBERCOM) 2017, Lisboa - PT.

Licença CC BY-NC atribuição não comercial. Com essa licença é permitido acessar, baixar (download), copiar, imprimir, compartilhar, reutilizar e distribuir os artigos, desde que para uso não comercial e com a citação da fonte, conferindo os devidos créditos de autoria e menção à Reciis. Nesses casos, nenhuma permissão é necessária por parte dos autores ou dos editores. 


\section{Introdução: comunicação, comum e sistemas comunicacionais}

Neste texto pretende-se discutir a circulação urbana e os equipamentos de transporte a partir de uma aproximação com certas noções de comunicação e cidadania. Entende-se a circulação como um importante modo histórico-político de uso, construção e ocupação do espaço público - uma prática de cidadania e um elemento fundamental na constituição do comum urbano - e os meios tecnológicos, bem como os espaços pelos quais ela se realiza - sistemas de transporte e espaços destinados ao deslocamento: ruas, avenidas, calçadas, trilhos, códigos de trânsito - como 'sistemas comunicacionais', ou seja, elementos mediadores da circulação - logo, da cidadania e do 'comum' - disputados pelo aparelho de estado, pelas forças mercadológicas e pelos corpos em movimento; com outras palavras, disputados pelas complexas e intempestivas camadas material, discursiva e intensiva do cotidiano das cidades.

Situamos nosso debate dentro dos limites conceituais da comunicação. Porém pela heterogenia e falta de coesão emblemáticas desse campo científico, antes de mais, faz-se necessário ressaltar algumas convenções basilares das quais partiremos. Originalmente, nos lembra Muniz Sodré, 'comunicar' - agir em comum ou deixar agir o comum - "[...] significa vincular, relacionar, concatenar, organizar ou deixar-se organizar pela dimensão constituinte, intensiva e pré-subjetiva do ordenamento simbólico do mundo"1. Nessa concepção radical de comunicação, os vínculos e as mediações não se limitam às estruturas representáveis da linguagem, são dinâmicos, movediços e se confundem entre mecanismos inconscientes, afetivos, sensitivos e corporais. A comunicação, desse modo, além de um terreno científico, componente do grande segmento das humanidades, será entendido, neste texto, não por sua faceta instrumental e técnica, nem por sua tradição midiática, jornalística ou publicitária, mas como um elemento constituinte do corpo social e das subjetividades ${ }^{1}$.

O elemento do 'comum' - objeto privilegiado da comunicação - assim, ao mesmo tempo em que se impõe como um recorte específico sobre o sócius, se desdobra em uma certa concepção teórico-política de humano, fundamentada não mais em unidades isoladas entre si ou transmissões, mas, ao contrário, em uma base teórico-conceitual que prima pelos planos relacional e vinculativo - ou, se quisermos, comunicacional. Desse modo, o humano pode ser considerado, na radicalidade do termo, um ser comunicante. Não porque fala ou está inserido em códigos linguísticos, estruturas sintáticas e semânticas, tampouco porque emite ou recebe mensagens e processa informações, mas porque é constituído necessária e fundamentalmente em 'comum': no e pelo que se passa no 'entre', no 'com', nos vínculos e relações coconstitutivas com o outro, com as coisas e com o mundo. Não se trata, assim, apenas do 'entre' do ser, mas do ser como 'entre’². São exatamente algumas interferências que se processam neste 'entre' do corpo social que nos interessarão a seguir; interferências no contexto dos equipamentos e tecnologias de transporte, as quais aproximamos do que Sodré ${ }^{1}$ nomeia como "sistemas comunicacionais".

O ‘comum', essa camada imensurável, irredutível e, portanto, irrepresentável da realidade social, está envolvido pela materialidade do mundo, suas agências e vetores de força. Surge com elas, e por elas segue sendo acompanhado em seu movimento constituinte permanente. Apesar de sempre resguardar um forte caráter de indeterminação e inapreensão, não pode ser pensado sem que as forças imediatas, tecnológicas e discursivas, dentro das quais está imerso, sejam consideradas. O 'comum', como vimos, se constitui na dinâmica dos encontros, porém os encontros não acontecem ao acaso; ao contrário, são cada vez mais instrumentalizados, manejados, organizados, alguns privilegiados em detrimento de outros. A partir de camadas espessas e complexas de objetos mediadores e organizativos, a comunicação vai se tornando progressivamente artificializada, midiatizada. Não é a artificialização por si que nos preocupa, porém. Afinal, como já mostrou Latour ${ }^{3}$, a artificialidade está e sempre esteve na base constitutiva do humano. Este se funda, diferenciando-se dos demais seres, justamente no agenciamento com os objetos com os 
quais se agencia com o mundo. O que de fato entendemos ser necessário problematizar é o vetor edificante, mercadológico e governamental que direciona essa camada mediadora dos sistemas comunicacionais.

É dentro dessa concepção constitutiva de comunicação, primeiro considerando o ‘comum' - os vínculos e as relações: os processos comunicacionais - como elemento mínimo do social e, segundo, a materialidade e a discursividade que envolvem essa trama social - os sistemas comunicacionais - que pensaremos doravante a circulação urbana, os sistemas de transporte e sua relação com uma certa concepção de cidadania.

\section{A circulação na formação e na funcionalização das cidades}

"A cidade é o correlato da estrada. Ela só existe em função de uma circulação e de circuitos; ela é um ponto assinalável sobre circuitos que a criam ou que ela cria. Ela se define por entradas e saídas, é preciso que alguma coisa aí entre e daí saia. Ela impõe uma frequência [...]. Ela representa um limiar de desterritorialização [...]”4.

A cidade, historicamente, desde a civitas romana, ao contrário de outras categorias territoriais como a aldeia, a vila e o campo, sempre foi o terreno privilegiado da diversidade, do estrangeiro e do estranhamento, do atrito e da negociação com o 'outro', do cotidiano intensivo e da ocupação do espaço público. Contudo, foi também sobre as cidades que as forças verticalizantes do estado e a axiomática capitalista incidiram de maneira mais enfática e violenta, principalmente a partir do século XIX. Assim como o 'ser' é aqui entendido a partir de um 'entre' constitutivo - o 'comum' -, interpelado e, em alguma medida, construído pela interferência do 'outro' e da materialidade do mundo, pensamos a cidade como uma instância territorial intensiva, movente, também comunal, sobre a qual as forças do estado/mercado operam instaurando estratos e funcionalidades - a cidade entendida como o território do 'comum', portanto.

Alguns pensadores, como Braudel 5 , Mumford ${ }^{6}$ e Deleuze-Guattari ${ }^{4}$, seguindo nessa direção de análise, realizaram o esforço teórico de diferenciar as maquinações urbanas, mercadológicas e estatais, no sentido de entender que essas instâncias produzem modos diversos de espacialidade e sociabilidade. Entretanto, apesar de entenderem que são dimensões e organizações diferentes, todos concordam que se trata, sobretudo na modernidade e no contemporâneo, de modos absolutamente imbricados de produção social e subjetiva e, de algum modo, inseparáveis analiticamente. A partir dessa colisão entre as intensidades da cidade, o aparelho verticalizador de estado e as forças mercadológicas, pensaremos, nesta secção, a urbanidade e sua circulação.

A cidade é um polo atrator, uma força centrípeta, um ímã, sugere Lewis Mumford: "[...] antes mesmo que a cidade seja um lugar de residência fixa, começa como um ponto de encontro: o ímã precede o recipiente"6. É a intensidade dos encontros, a mistura de pessoas, línguas, costumes e objetos de procedências diversas que cria e sustenta essa categoria, aliás, mais social que espacial. A cidade, por esse viés, pode ser entendida mais como um modo intensivo de organização do socius que como um recorte geográfico, populacional e governamental, e traz a circulação como um dos pontos mais elementares de seu funcionamento.

Propriamente como categoria da ciência ocidental - antes mesmo da urbanidade se tornar a tônica político-econômica do mundo - a circulação aparece pela primeira vez no século XVII, com a descoberta da dimensão microscópica do corpo e, por consequência, do sistema sanguíneo humano, por William Harvey. Sua descoberta, além de uma nova concepção de saúde, fundamentada nas impressões da dinâmica sanguínea - já muito marcadas pelas noções de velocidade e funcionalidade -- inspirou conclusões sobre a organização social, financeira e territorial das cidades.

Sennett vai mostrar em 'Carne e Pedra', como os termos e os anseios do liberalismo moderno, encabeçado por Adam Smith, já no século XVIII, coincidiram com as concepções de saúde do organismo: se a saúde do corpo, a partir de Harvey, passava a ser mensurada pela capacidade dos leucócitos e hemácias de transportar os nutrientes e o oxigênio pelo plasma sanguíneo de um ponto específico a outro no corpo, a 'saúde' econômica de uma nação, dentro das concepções liberais de Smith, passava a 
ser medida, analogamente, pela circulação veloz e eficiente de dinheiro e mercadorias - logo, de pessoas - pela cidade: “[...] quanto mais circulação houver, quanto mais especializado for o trabalho, maior será o número de atores individuais"'.

Um terceiro movimento nesse sentido, também lembrado por Sennett ${ }^{7}$, se processa no contexto das intervenções do Barão de Haussmann sobre o espaço urbano parisiense na segunda metade do século XIX. Foi Haussmann que, pela primeira vez, marcou no solo de uma cidade ocidental as condições estruturais para que a mecânica liberal da circulação se processasse de maneira plena. O conceito circulatório de saúde alcançava, enfim, a morfologia das cidades e, assim, a materialidade cotidiana dentro da qual os corpos urbanos passariam a experimentar os espaços.

Esse movimento progressivo e progressista de intervenções verticais sobre o espaço público das cidades teve continuidade no século XX com Le Corbusier, um dos expoentes dos Congressos Internacionais de Arquitetura Moderna (CIAM). Admirador confesso do barão francês, Corbu propunha o que chamou de 'cidade funcional', um modelo urbanístico que tinha seu funcionamento e sua estrutura organizados dentro de quatro funções básicas: trabalhar, habitar, recrear e circular. A circulação, mais uma vez, ocupava papel central nessa dinâmica - não mais como elemento intempestivo e constituinte, mas, ao contrário, como dimensão estrutural da funcionalidade - uma vez que era por meio dela que o eixo mais importante trabalhar-habitar - poderia funcionar plenamente.

Alguns tópicos da famosa Carta de Atenas, organizada por Le Corbusier após o $4^{\circ}$ Congresso de Arquitetura Moderna (CIAM), em 1933 - e que depois se tornará a base da chamada 'cidade funcional' - são emblemáticos nesse aspecto: "Os trajetos entre as habitações e os locais de trabalho deviam ser diretos e percorríveis no menor tempo possível [...]. A largura insuficiente das ruas é a causa dos congestionamentos do tráfego [...]. Um novo sistema viário adequado aos meios modernos de transporte torna-se, pois, necessário. [...]. Estabelecer conexões entre os locais de moradia, trabalho e recreação, de forma tal que o ciclo diário das atividades se processe, em cada setor, com a maior economia de tempo, subordinado, como está, a um fator constante - a rotação da terra em torno de seu eixo"8.

Tendo os fins (o lar, o trabalho, as instituições) ganhado protagonismo em relação aos meios (as ruas), a vida pública e a intempestividade propriamente urbana, tão emblemáticas na formação das cidades ocidentais, vão rapidamente sendo esvaziadas de suas funções políticas e econômicas. Um movimento de interiorização, institucionalização e domesticação vai rapidamente impondo a substituição dos espaços públicos por espaços privados. A rua, pouco a pouco, deixa de ser o local privilegiado dos encontros e das indeterminações para se tornar um espaço estéril, previsível, sem grandes atrativos afetivos e sensitivos para os corpos.

Em perspectiva, partindo da fisiologia do corpo (XVII), passando pela economia (XVIII) até o solo, as habitações e as instituições da cidade (XIX e XX), percebemos estar em processo, ao longo desses quatro últimos séculos de manipulação e funcionalização da circulação, um só movimento, contínuo, de canalização das funções coletivas, políticas e econômicas da cidade para interiores domésticos, individuais e privados, em prejuízo das relações coletivas e dos espaços públicos.

Propriamente sobre os sistemas de transporte, que serão determinantes na funcionalização da circulação, podemos, talvez, pensar um movimento em quatro camadas territoriais cumulativas de interiorização e afastamento da vida pública: 1) a calha viária; 2) a atomização dos corpos no interior dos modais; 3) a inserção cognitiva e atencional nos códigos e indicações do trânsito; e, 4) as altas velocidades permitidas dentro dessas condições espaciais e normativas. Essas camadas certamente sofrem variações de intensidade de acordo com o transporte utilizado, todavia o caso do motorista automotivo nos parece ser o mais paradigmático nesse sentido. De todos os modos de experienciar a circulação urbana, o dirigir talvez seja o que se relaciona de maneira mais profunda com a normatividade funcional e liberal das cidades. Sua velocidade, suas possibilidades de contorno, o local de sua parada, sua relação com os 
demais motoristas e partícipes do trânsito, tudo isso está organizado para acontecer da maneira mais previsível e mecânica possível.

Quase todas as interações do motorista com o que se passa fora de sua cabine estão mediadas por luzes e símbolos, que podem ser captados e seguidos a partir do distanciamento próprio da visão. Os demais sentidos - tato, olfato e audição -, bem como as sensações corporais, parecem estar muito mais voltadas para a ambientação interna do modal que para uma relação com o exterior - com a cidade. Mesmo as referências espaciais outrora importantes para a localização e o desenrolar do percurso já deixam de ser fundamentais com a popularização dos GPS's. O motorista é condicionado a ser quase um autômato quando segue seu trajeto, tanto que o carro sem motorista já é uma realidade.

É exatamente considerando nuances do uso do automóvel e a experiência circulatória do motorista que Sennett ${ }^{7}$ vai falar de uma crise táctil das cidades modernas. Ao longo do século XX, os modais e as condições espaciais vão se adequar de tal modo aos fundamentos da circulação liberal que a relação dos corpos com os espaços públicos passará a ser cada vez mais de ultrapassagem, de deslizamento, e cada vez menos de interação e vinculação. Sem atrativos sensíveis e vinculativos para os corpos, as cidades tornam-se, assim, meros espaços de passagem, espaços que despertam apenas o desejo de travessia: "deslocar-se ajuda a dissensibilizar o corpo [...] cidades cheias de espaços neutros, cidades que sucumbiram à força maior da circulação"”.

Peixoto $^{9}$ também aborda essa problemática quando fala de um processo sensitivo de planificação do espaço quando experienciado pelos corpos que se deslocam em alta velocidade nos automóveis. Planificação esta que indica, além de uma bidimensionalização sensório-espacial, um modo superficializado de se encontrar com os elementos ao redor: "a velocidade provoca, para aquele que avança num veículo, um achatamento da paisagem. Quanto mais rápido o movimento, menos profundidade as coisas têm, mais chapadas ficam [...] a paisagem urbana se confundindo com outdoors".

A perspectiva crítica às consequências degradantes sobre sensitividade na vida urbana não é recente. Simmel $^{10}$, já na virada para o século XX, ressaltava certa incompatibilidade fisiológica entre a capacidade de apreensão cognitiva do corpo e o excesso de estímulos proporcionado pelas grandes cidades, o que, segundo ele, produziria uma redução da atividade interativa, resultando no que chamou de atitude blasè. O que o autor imputava à urbanidade, porém, nós entendemos estar localizado não na cidade em si, mas propriamente nas condições de possibilidade da circulação moderna, sobretudo eu seu caráter liberal, de individualização e funcionalidade. Baudelaire ${ }^{11}$, já naquela época, se contrapõe a Simmel quando descreve a figura do Flaneur que, apesar de seu modo de vida deslocado das obrigações trabalhistas mais comuns naqueles tempos, consegue se dispor com mais vagar à captação dos estímulos, explicitando uma experiência prazerosa de imersão e contemplação da saturação urbana.

É em conexão com as condições sensitivas do motorista e com o deslocamento motorizado do automóvel, portanto, que são conduzidos os desenhos das vias urbanas e, muitas vezes, do espaço público como um todo. Vimos, até aqui, que isso implica um modo de urbanidade cada vez menos propenso à livre ocupação e uso da cidade. Contudo, além da dimensão sensitiva, relacionada aqui com um tipo específico de modal e com a morfologia dos espaços, temos um outro tipo de restrição, muito comum no Brasil, que se soma a esse e que atinge principalmente uma parcela mais pobre da população: a restrição ao uso dos transportes coletivos, seja ela tarifária ou estratégica, como no caso do corte de algumas linhas de ônibus, ou da limitação de horários de funcionamento etc. Essa limitação, diferente da operada pelo automóvel, se relaciona mais diretamente ao tema da cidadania, pois implica imediatamente em restrições do direito civil de livre locomoção, ou, se quisermos, do direito de ir e vir. 


\section{Transportes coletivos, direito de ir e vir e cidadania}

Além das limitações sensitivas - processadas no contexto da organização automotiva da circulação urbana e que influem diretamente no modo como nos relacionamos e vinculamos, isto é, nos comunicamos, na e com a cidade - trataremos agora de um modo de limitação mais direto e explícito, relacionado não mais ao modo como os corpos experienciam os transportes e as vias, mas exatamente o contrário: à impossibilidade de utilizar os sistemas coletivos de transporte e se deslocar pelos perímetros urbanos cada vez mais abrangentes e hostis. Impossibilidade esta que pensamos se estruturar e sustentar de dois modos principais: pela tarifa cobrada no acesso ao transporte, ou seja, pela transformação da circulação em mercadoria; e, segundo, pela definição estratégica de trajetos, paradas e horários, de modo a privilegiar certos circuitos - bairros, regiões, populações, horários - em detrimento de outros. Um modo capitalístico e outro estatal, portanto.

Os dois processos - organização viária e restrição aos transportes - se conjugam. Como mostra Kuster ${ }^{12}$, na medida em que as cidades crescem em extensão e complexidade, os transportes motorizados tornamse cada vez mais necessários para os deslocamentos cotidianos, o que produz, como consequência, como vimos na secção anterior, um processo de esvaziamento político dos espaços públicos, já que este passa a ser construído e organizado prioritariamente para o fluxo dos automóveis e coisas e não mais para os corpos e os encontros. O espaço público feito para um modal motorizado em deslocamento veloz naturalmente tende a tornar-se hostil ao corpo, de modo que os transportes fechados sejam, por mais este motivo, demandados. Ao cabo, na dinâmica de restrição tarifária aos transportes, temos a exclusão de toda uma parcela mais pobre da população não apenas do transporte, como também da circulação, uma vez que o primeiro se torna fundamental para essa atividade. Isso se agrava ainda mais se considerarmos que, via de regra, as populações menos privilegiadas residem em regiões afastadas dos polos econômicos, onde normalmente são oferecidos mais serviços e oportunidades de trabalho.

Na radicalidade da questão, quando pensamos em restrições tarifárias e estratégicas em uma metrópole com os índices de pobreza do Rio de Janeiro, por exemplo, estamos falando de um modo bastante direto e violento, mas, proporcionalmente, naturalizado, de limitação do direito civil de livre deslocamento, ou, como é mais conhecido, do direito de ir e vir. No caso do Rio - e arriscamos uma generalização para todas as capitais brasileiras - cobrar pela passagem, sobretudo os altos valores atuais, é, objetivamente, impedir que os mais pobres circulem pela cidade. É dentro das tramas desse debate que fazemos encontrar, enfim, a discussão da circulação urbana com questões mais próprias de cidadania.

Antes de mais, é importante explicitar o que pretendemos indicar quando insistimos no uso desse termo, notadamente desgastado pelos usos genéricos. Segundo José Murilo Carvalho ${ }^{14}$, a ideia de cidadania marca a hegemonia da sociedade de direito sobre os regimes senhoriais, isto é, o intenso processo de transição do medievalismo rural e servil para a vida urbana, estatal e de trabalho dito livre. Uma transição, segundo Habermas ${ }^{14}$, orquestrada pelas elites urbanas que precisavam encaixar a população flutuante que chegava do campo em categorias, funções e espaços formais nas cidades que se adensavam rapidamente. A emergência da noção de cidadania - entendido aqui como o enfeixamento dos direitos civis, políticos e sociais - é central nessa passagem.

No Brasil, segundo Carvalho ${ }^{13}$, foi seguido o modelo alemão de cidadania, com fluxo de cima para baixo e atuação no espaço privado, ainda que o país não compartilhe a tradição germânica de obediência às leis. A cidadania teria sido construída dentro de uma cultura paroquial, tendendo para uma cultura súdita. Por isso ele a conceitua como "estadania" ${ }^{3}$. Na estadania, o estado é central e não tem caráter público ou universalista. Carvalho argumenta que, no Brasil, os direitos políticos teriam vindo primeiro, mas que, da mesma maneira que na Europa, os direitos do homem estavam fundidos e foram gradativamente sendo separados em direitos civis, políticos e sociais. 
Entretanto, é preciso considerar que essa atuação verticalizada do estado sobre as populações não era recebida sempre de maneira pacífica. Existem exemplos históricos desde o século XIX, não apenas de reações muito violentas, na forma de revoltas populares bastante abrangentes, como também de ações coletivas propositivas. É o caso dos movimentos contra o alistamento militar obrigatório - lei de 1874; contra o registro civil, inclusive o casamento, no mesmo ano; contra o novo sistema de pesos e medidas, em 1871 no Rio de Janeiro etc. Um exemplo contemporâneo emblemático foram as manifestações de 2013, que apesar de terem sido impulsionadas pelo aumento arbitrário das tarifas, se organizavam inicialmente em torno da proposta clara do transporte público gratuito - o chamado 'passe livre'. Carvalho designou essas ações propositivas, que se davam de baixo para cima, por "cidadania em negativo"13.

É preciso referenciar que, por 'direitos civis', entende-se a liberdade individual de expressão, de fé e de propriedade. Os 'direitos políticos' estão no âmbito da participação da população no poder, diretamente, como eleitor ou eleito. Como 'direitos sociais', enfim, coloca-se a participação ao direito mínimo de bemestar econômico e segurança, e ainda de educação, alimentação, saúde etc. Segundo o estudo clássico desenvolvido por Marshall ${ }^{15}$, os direitos surgiram em períodos diferentes: os civis, no século XVIII; os políticos, no XIX; e os sociais no XX. Para Carvalho, porém, no caso brasileiro, a separação funcional desses direitos acarretou uma dificuldade de acercamento da visão de cidadania, resultando numa concentração sintética nos direitos políticos, como se apenas a via eleitoral - o voto e a consequente escolha de representantes - fosse suficiente para se garantir a plenitude cidadã. A conceituação de Marshall entende a cidadania como um status universal, enriquecida pelos direitos e regulada pelos contratos.

O contrato moderno é essencialmente um acordo entre os livres e iguais em status, embora não necessariamente em poder. O status não foi eliminado do sistema social. O status diferencial, associado com classe, função e família, foi substituído pelo único status uniforme de cidadania, que ofereceu o fundamento da igualdade sobre o qual a estrutura da desigualdade foi edificada ${ }^{15}$.

O caso do direito de livre locomoção, que no Brasil é contemplado como um direito civil básico, é ilustrativo nesse aspecto de um direito amplo e genérico que esconde, ou até mesmo legitima, a manutenção de alguns desníveis cotidianos. Na lei, a liberdade de locomoção pela cidade, por exemplo, não considera as condições básicas desse deslocamento. Ou melhor, por não detalhar as nuances condicionantes dos cidadãos - o preço em relação à pobreza da população, a precariedade dos sistemas de transporte, as limitações estratégicas das linhas, paradas e horários etc. - acaba por considerar sim, ou que todos partem das mesmas condições econômicas e materiais para se locomover, ou que os cidadãos são livres para circular com seus corpos, independente das condições materiais disponíveis. Nos dois casos, percebe-se exatamente esse exemplo destacado por Marshall, de um discurso genérico em favor de uma liberdade que permite a manutenção dos cerceamentos mais agudos.

É partindo desse ponto que se estrutura o argumento do movimento Passe Livre na proposta de que os transportes coletivos sejam gratuitos, de qualidade e, em alguns casos, de funcionamento permanente. Eles defendem justamente que a circulação, isto é, as condições materiais específicas para que ela aconteça, seja considerada na radicalidade do termo, um direito básico, acessível a todos, e não uma mercadoria, como tradicionalmente acontece nas cidades brasileiras. $\mathrm{O}$ argumento justificase também porque a produtividade urbana está cada vez mais associada à 'cidade-mercadoria', isto é, à cidade que funciona mais como polo de atração de investimentos do que espaço de habitação e sociabilidade. A cidade torna-se prioritariamente um espaço de atravessamento dos fluxos de consumo em toda a sua complexidade, transformando-se de centro tecnosocial da produção industrial em centro administrativo de forças alternativas à clássica força de trabalho. Na cidade-mercadoria, os direitos sociais são mercantilizados por grupos empresariais em conluio com o poder público, fazendo com que urbanismo, educação, saúde, mobilidade e segurança entrem na lógica dos preços ascendentes. 
Na sociedade moderna, os 'direitos sociais' (educação, saúde, habitação, proteção coletiva) são posteriores aos 'direitos civis' (representação democrática, liberdade de expressão, locomoção etc.). A luta sob a bandeira dos direitos sociais (no Brasil, o foco gerativo desses direitos é a Constituição Federal de 1988 ${ }^{16}$, que os transferiu do capítulo da Ordem Econômica para o da Ordem Social, reinterpretando-os como direitos universais de cidadania) contribui para ampliar o conceito de cidadania como apropriação social de bens coletivos. Uma coisa, porém, é o formalismo dos direitos, outra é o seu exercício efetivo. Daí, a dissonância ideológica entre o ativismo em prol da universalização dos direitos sociais e a valorização neoliberal da lógica do mercado, afim à privatização na apropriação dos bens coletivos implicados nos direitos sociais. Nesse embate - cujo pano de fundo teórico é a discussão sobre o direito de ir e vir - aparece a diferença entre liberdade e liberalismo.

\section{Considerações finais: circulação, cidadania e o 'comum' urbano}

Neste texto buscamos relacionar, a partir de uma visada comunicacional, circulação urbana e cidadania. Na esteira do pensamento de Muniz Sodré ${ }^{1}$, entendemos a comunicação, como propõe o autor, como a "ciência do comum", isto é, o campo científico que encontra sua especificidade problemática no estudo das relações e dos vínculos - do ser como 'entre' -, bem como das forças materiais e discursivas que incidem sobre estes. Por um lado, a comunicação como o estudo dos processos comunicacionais e, por outro, dos "sistemas comunicacionais".

A cidade, em um segundo momento, é pensada a partir de Mumford ${ }^{6}$, Braudel ${ }^{5}$ e Deleuze-Guattari ${ }^{4}$, como um território intensivo de sociabilidade, marcado pelo encontro com a diversidade e pela emergência, ocupação e disputa do espaço público. Nessa concepção de urbanidade, a 'circulação' tem função basilar tanto em seu surgimento como em sua funcionalização verticalizante - função constituinte e estruturante, portanto. Vimos ainda neste tópico como, ao longo dos últimos quatro séculos, a manipulação da circulação, a rodoviarização das cidades e o privilégio do modo motorista de experienciar os espaços foram preponderantes no processo de esvaziamento dos espaços públicos de suas funções política, relacional, afetiva e vinculativa.

Por fim, trabalhamos o esvaziamento dos espaços púbicos pela perspectiva da cidadania. Um esvaziamento operado desta vez pela imposição de tarifas e limitações estratégicas de linhas, itinerários, horários, paradas etc., que, na prática, funcionam como fatores que restringem certas classes sociais ao uso dos sistemas de transporte e, por consequência, ao direito civil de livre deslocamento - ou, como mais conhecido, ao direito de ir e vir.

\section{Referências}

1. Sodré M. A ciência do comum: notas para um método comunicacional. Petrópolis: Vozes; 2014.

2. Esposito R. Communitas: origen y destino de la comunidad. Buenos Aires: Amorrortu; 2007.

3. Latour B. Reagregando o social. Salvador: Edufba; 2012.

4. Deleuze G, Guattari F. Mil platôs: capitalismo e esquizofrenia 2. São Paulo: Editora 34; 2012, v. 5.

5. Braudel F. Civilização material, economia e capitalismo. São Paulo: Martins Fontes, 1995.

6. Mumford L. A cidade na História. Belo Horizonte: Itatiaia; 1965.

7. Sennett R. Corpos em movimento. Rio de Janeiro: Bestbolso, 2008. Carne e pedra: o corpo e a cidade na civilização ocidental; p. 261-289.

8. Sampaio AHL. (Outras) Cartas de Atenas: com textos originais. Salvador: Quarteto, 2001. p. 40-45.

9. Peixoto NB. O olhar do estrangeiro. In: Novaes A, organizador. O Olhar. São Paulo: Companhia das Letras; 1988. p. 361-365. 
10. Simmel G. A metrópole e a vida mental. In: Velho O, organizador. O fenômeno urbano. Rio de Janeiro: Zahar; 1973. p. 11-25.

11. Baudelaire C. O pintor da vida moderna. Belo Horizonte: Autêntica; 2010.

12. Kuster E. Quando nossos movimentos definem as cidades: a circulação como demarcação morfológica das metrópoles. Rev Digital E-metrópolis [Internet]. 2012 set [citado em 2019 jul. 24];10:3. Disponível: http://emetropolis.net/artigo/83?name= quando-nossos-movimentos-definem-as-cidades-a-circulacaocomo-demarcacao-morfologica-das-metropoles.

13. Carvalho JM. Os bestializados da República. São Paulo: Companhia das Letras; 2004.

14. Habermas J. L'inclusione dell' altro - studi de teoria política. Milão: Editora Feltrinelli; 1998.

15. Marshall TH. Cidadania, classe social e status. Rio de Janeiro: Zahar Editores; 1967.

16. Brasil. Constituição, 1988. Constituição da República Federativa do Brasil. Brasília: Senado Federal; 1988. 